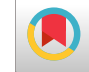

\title{
Surgical Site Infection in a 1000-Bed Tertiary-Care Teaching Hospital in New Delhi, India
}

\author{
Inam Danish Khan ${ }^{1}$, Akanksha Yadav ${ }^{2}$, Umesh Kapoor ${ }^{3}$, Ishitta Joshi ${ }^{4}$, Rahul Pandey (iD ${ }^{5,}{ }^{*}$, Ananta \\ Kumar Naik $^{5}$, Jyoti Prakash ${ }^{6}$, Abhimannyu Chowdhury ${ }^{6}$, Megha Brijwal ${ }^{7}$, Geetanjali Gonimadatala ${ }^{2}$, \\ Nehal Bhuttay ${ }^{2}$ and Anuradha Makkar ${ }^{8}$ \\ ${ }^{1}$ Classified Specialist Microbiology, Command Hospital (Northern Command), Udhampur, India \\ ${ }^{2}$ III MBBS, Army College of Medical Sciences, New Delhi 110010, India \\ ${ }^{3}$ Senior Adviser Pathology and Head Pathology, Command Hospital (Northern Command), Udhampur, India \\ ${ }^{4}$ Research Scholar, Vellore Institute of Technology, Vellore, India \\ ${ }^{5}$ Army College of Medical Sciences and Armed Forces Clinic, New Delhi 110010, India \\ ${ }^{6}$ Army Hospital Research and Referral, New Delhi 110010, India \\ ${ }^{7}$ Clinical Microbiology and Infectious Diseases, All India Institute of Medical Sciences, New Delhi 110029, India \\ ${ }^{8}$ Army College of Medical Sciences and Base Hospital, New Delhi 110010, India \\ "Corresponding author: Assistant Professor Surgery, Army College of Medical Sciences and Armed Forces Clinic, New Delhi 110010, India. Email: rahuladviksimpy@gmail.com
}

Received 2020 July 13; Accepted 2020 August 19.

\begin{abstract}
Background: Surgical site infection (SSI) includes infections occurring after 48 hours of any surgery and accounts for most of the healthcare-associated infections (HAIs) in surgical centers. Surgical site infections can result in pain, discomfort, prolonged hospital stay, increased exposure to antimicrobials, and consequentially, increased healthcare costs.

Objectives: The study intended to characterize the incidence, etiology, and emerging resistance of SSI in a 1000-bed tertiary-care teaching hospital in New Delhi.

Methods: The ambispective study was conducted in a 1000-bed tertiary-care teaching hospital in New Delhi. Clinical, laboratory, and environmental surveillance and screening of health care providers (HCPs) were conducted using the National Healthcare Safety Network (NHSN) definitions and methods given by the US Centers for Disease Control and Prevention (CDC).

Results: With 3,541 patients admitted to the Gynecology and Obstetrics Ward and General Surgical Ward of the hospital, the total episodes of SSI were 80 (2.26\%). The mean rates of superficial, deep, and organ space SSI were $46.25 \%, 47.5 \%$, and $6.25 \%$, respectively. The most common organisms isolated were Acinetobacter baumannii (23.75\%), Pseudomonas aeruginosa (17.5\%), Escherichia coli (15\%), and Staphylococcus aureus (12.5\%).

Conclusions: The rate of SSI in our study was comparable to the unadjusted rates in India, lower-middle, upper-middle, and highincome countries worldwide. Patients with pre-existing medical illness, prolonged operation time, and wound contamination are strongly predisposed to surgical site infection.
\end{abstract}

Keywords: Surgical Site Infection (SSI), Device-Associated Healthcare-Associated Infections (DA-HAI), US Centers for Disease Control and Prevention (CDC)

\section{Background}

Surgical site infection (SSI) is defined as infection occurring after 48 hours of any surgical intervention affecting incised superficial tissue, deep tissue, or organ spaces at or around the site of surgery. Surgical site infection includes the most common healthcare-associated infections (HAIs) in surgical centers, accounting for up to 15\% of HAIs. The analysis of 220 international studies of SSI in developing countries in the year 2010 showed the incidence of SSI as low as $0.4 \%$ to as high as $30.9 \%$. The SSI rates in India vary from $6 \%$ to $38.7 \%(1-4)$.
Microbial contamination during pre, intra, or postoperative periods results in SSI due to either exogenous pathogens such as Staphylococcus, Streptococcus, and Pseudomonas acquired after breakthrough sterilization protocols from contaminated surgical instruments or operating room air contamination, or endogenous pathogens such as methicillin-resistant Staphylococcus aureus (MRSA), coagulase-negative staphylococci, Enterococcus species, and E. coli opportunistically infecting wounds. Most pathogens causing SSI are multidrug-resistant (5-10).

Surgical site infection can result in fever, pain, discom-

Copyright (c) 2020, Journal of Archives in Military Medicine. This is an open-access article distributed under the terms of the Creative Commons Attribution-NonCommercial 4.0 International License (http://creativecommons.org/licenses/by-nc/4.0/) which permits copy and redistribute the material just in noncommercial usages, provided the original work is properly cited. 
fort, prolonged hospital stay, increased exposure to antimicrobials, and consequentially, increased healthcare costs. Meticulous surgical procedures of short duration taken place in a clean and hygienic environment and administration of prophylactic antimicrobials can decrease the risk of SSI. The risk of infection is higher during emergency surgery and minimal when the subcutaneous tissue is well perfused and oxygenated with no dead space. A large number of host factors such as diabetes mellitus, hypoxemia, hypothermia, leucopenia, long term use of steroids, nicotine, malnutrition, poor skin hygiene, etc. also can contribute to increasing the chances of SSI development (11, 12).

Periodic surveillance and feedback have been proven to reduce the rates of SSI. The United States Centers for Disease Control and Prevention (US-CDC) have given fresh guidelines on SSI in 2017 after feedback from the Healthcare Infection Control Practices Advisory Committee (HICPAC) (13).

\section{Methods}

This prospective study was conducted among all patients admitted to a 1000-bed tertiary-care teaching hospital in New Delhi for five months from May 2018 to September 2018, after approval of the Institutional Ethics and Scientific Committee. All good clinical practices and laboratory guidelines were observed. Patients staying less than 48 hours, testing positive for infections within 48 hours, or showing evidence of existing infections on admission were excluded.

\subsection{Sample Collection, Transportation, and Processing}

Samples were collected from the site of SSI such as the incision site and drain fluid following strict aseptic techniques. The samples were immediately transported to a microbiology lab for cultures on blood and MacConkey agars and incubated for $24-48$ hours at $37^{\circ} \mathrm{C}$. Organism identification and antimicrobial susceptibility were done through standard microbiology techniques employing routine bacteriological methods, Kirby Bauer Disk Diffusion method, and/or VITEK-2 Compact Automated Microbiology system. Non-repeat positive cultures with respective antibiograms were utilized for profiling of isolates and antimicrobial susceptibility. The patient's demographic profile was noted from the patient's charts/requisition form.

\subsection{Data Collection and Analysis}

Data were collected from antibiogram patterns obtained through zone sizes from Kirby Bauer disk diffusion and/or minimal inhibitory concentration from the Vitek2 compact automated microbiological system. The data were analyzed descriptively through Microsoft Excel and SPSS version 21 using appropriate tests.

\section{Results}

The analysis was done on the data of 3,541 patients admitted to both Gynecology-Obstetrics Ward and GeneralSurgical Ward of the hospital between 1, May 2018 and 30, September 2018 who underwent surgical interventions. Of them, 3,076 (86.87\%, 95\% Confidence Interval (95\% CI): $85.7 \%$ to $87.96 \%$ ) patients stayed in the hospital for more than 48 hours (Figure 1).

The common sterilization methods were autoclaving, plasma-sterilization, and ethylene oxide. Various antiseptics used for hand-hygiene were Povidone-iodine scrub solution, Savlon scrub solution, and soap. Cefotaxime $2 \mathrm{gm}$ or cefoperazone $2 \mathrm{gm}$ was used as a prophylactic antimicrobial agent one hour before surgery for uncomplicated cases for both general-surgery and gynecological procedures. The mean preoperative hospital stay and postoperative stay of the patients were $6.57 \pm 12.7$ and $19.25 \pm 7.92$ days, respectively. Besides, $43 / 80$ (53.75\%, 95\% CI: 42.3\% to $64.84 \%$ ) were males, with a male to female ratio of 1.16:1 (Figure 2).

The overall rate of SSI was 80/3541 (2.26\%, 95\% CI: $1.81 \%$ to $2.82 \%)$. The highest incidence of SSI was noted in 51 - 60 years of age as $22 / 80$ (27.5\%, 95\% CI: 18.4 to $38.8 \%$ ) (Figure 3 ), while the lowest incidence was found in the age group of 13 - 20 years as $4 / 80$ ( $5 \%$, 95\% CI: $1.6 \%$ to $12.9 \%$ ).

The mean duration of surgery was 4.5 hours. Besides, $23 / 80$ (28.75\%, $95 \%$ CI: $19.45 \%$ to $40.12 \%$ ) patients had comorbidities such as diabetes mellitus [19/80 (23.75\%, 95\% CI: $15.25 \%$ to $34.81 \%)]$ and hypertension [15/80 (18.75\%, 95\% CI: $11.21 \%$ to $29.35 \%)$. Moreover, $34 / 80$ (42.5\%, 95\% CI: $31.68 \%$ to $54.05 \%)$ patients presented with mild fever while $16 / 80$ (20\%, 95\% CI: $12.2 \%$ to $30.74 \%$ ) patients presented with body temperature between $100^{\circ} \mathrm{F}$ and $103^{\circ} \mathrm{F}$. However, $29 / 80$ (36.75, 95\% CI: $26.01 \%$ to $47.82 \%$ ) patients did not show any rise in temperature (Figure 4 ).

The WBC count was raised in $24 / 80$ (30\%, 95\% CI: $20.52 \%$ to $41.42 \%$ ) patients (Figure 5 ).

Moreover, 21/80 (26.25\%, 95\% CI: 17.33 to $37.48 \%$ ) patients had pyrexia, increased leukocyte count, and tachycardia, thus falling under major SSI while remaining 59/80 (73.75\%, 95\% CI: 62.52 to 82.67) patients developed minor SSI (Figure $6)$.

According to the CDC guidelines, superficial SSI was 37/80 (46.25\%, 95\% CI: $35.2 \%$ to $57.7 \%$ ), deep SSI was $38 / 80$ (47.5\%, 95\% CI: $36.34 \%$ to $58.9 \%$ ), and organ space SSI was 5/80 (6.25\%, 95\% CI: $2.32 \%$ to $1.46 \%$ ) (Table 1 and Figure 7 ). 


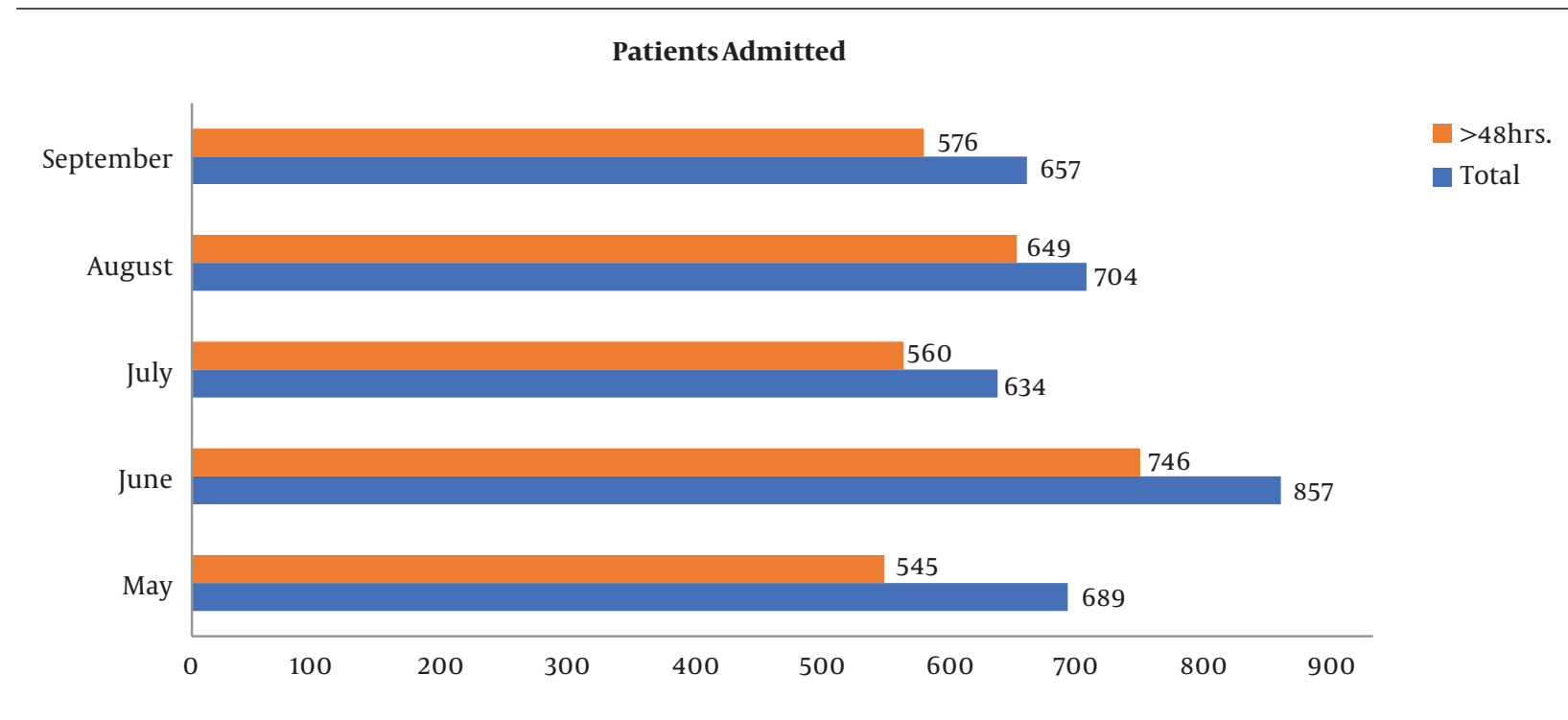

\begin{tabular}{|c|c|c|c|c|c|}
\hline Month & Total & $>48 \mathrm{~h}$ & Superficial & Deep & Organ Space \\
\hline May & 689 & 545 & 7 & 6 & 1 \\
\hline June & 857 & 746 & 11 & 9 & 0 \\
\hline July & 634 & 560 & 5 & 6 & 0 \\
\hline August & 704 & 649 & 8 & 7 & 1 \\
\hline September & 657 & 576 & 6 & 10 & 3 \\
\hline
\end{tabular}

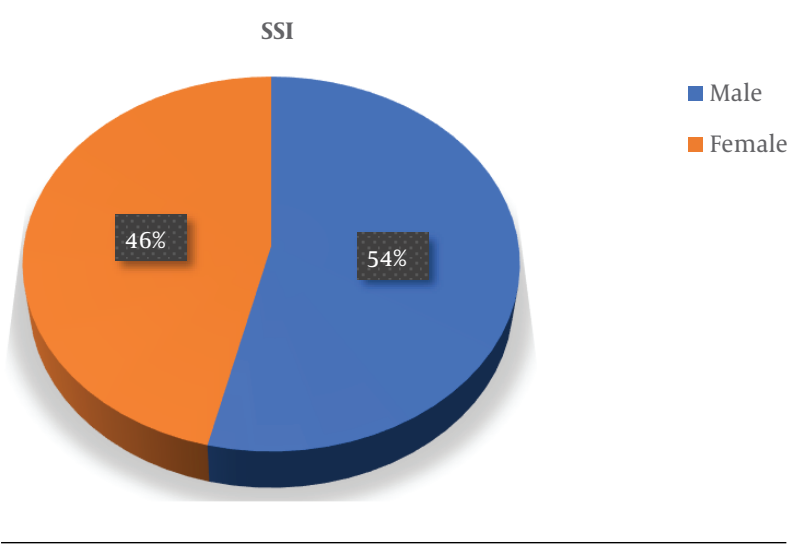

Figure 2. Gender of patients with SSI in a 1000-bed tertiary-care teaching hospital

Gram-negative bacteria caused the highest rate of SSI as $65 / 80(81.25 \%, 95 \% \mathrm{CI}: 70.65 \%$ to $88.8 \%)$ wherein the most common pathogen was Acinetobacter baumannii as 19/80 (23.75\%, 95\% CI: $15.25 \%$ to $34.81 \%)$, followed by Pseudomonas aeruginosa as $14 / 80$ (17.5\%, 95\% CI: $10.23 \%$ to $27.96 \%)$. Gram-

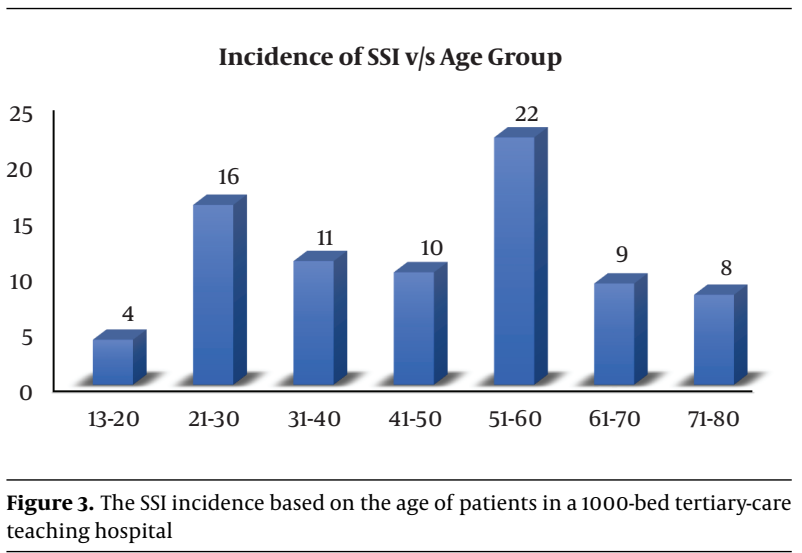

positive bacteria accounted for only 15/80 (18.75\%, 95\% CI: $11.2 \%$ to $29.35 \%$ ) episodes of SSI (Figure 8 ).

\section{Discussion}

The overall incidence of SSI in this 1000-bed tertiarycare hospital was $2.6 \%$, which is comparable to the rates 


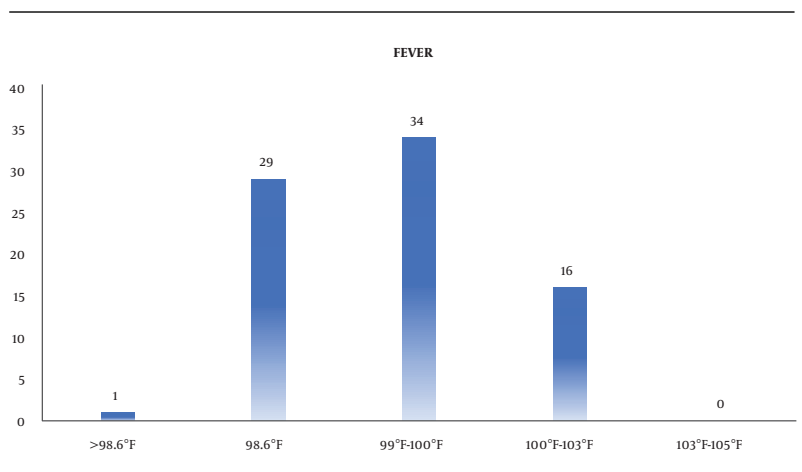

Figure 4. Fever in SSI patients in a 1000-bed tertiary-care teaching hospital

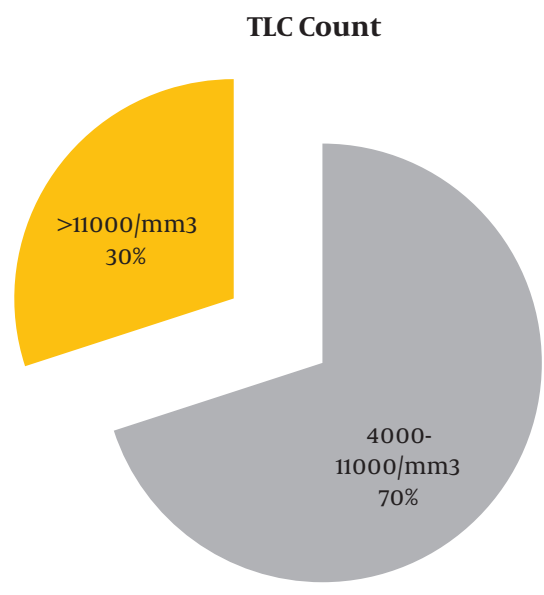

Figure 5. TLC of patients with SSI in a 1000-bed tertiary-care teaching hospital

in other studies in other parts of the world and India, i.e., $2.5 \%$ to $38.7 \%$. There was a marginal preponderance of male patients (54\%) over female patients (46\%) developing SSI. In some studies, female preponderance was reported, but sex is not a pre-determinant factor towards the risk of SSI. The highest incidence was observed in the 51- 60 years' age group. Studies have reported that the increasing age independently predicted an increased risk of SSI until the age of 65 years, while at ages $\geq 65$ years, the increasing age independently predicted a decreased risk of SSI. The average duration of surgery was 4.5 hours among patients who developed SSI. Prolonged operation time, increased exposure to the operation theater air, prolonged anesthesia, prolonged trauma, and sometimes, excessive blood loss can increase the risk of SSI. Certain conditions like hyperglycemia and hypertension predispose an individual to SSI according to various studies (14-17).

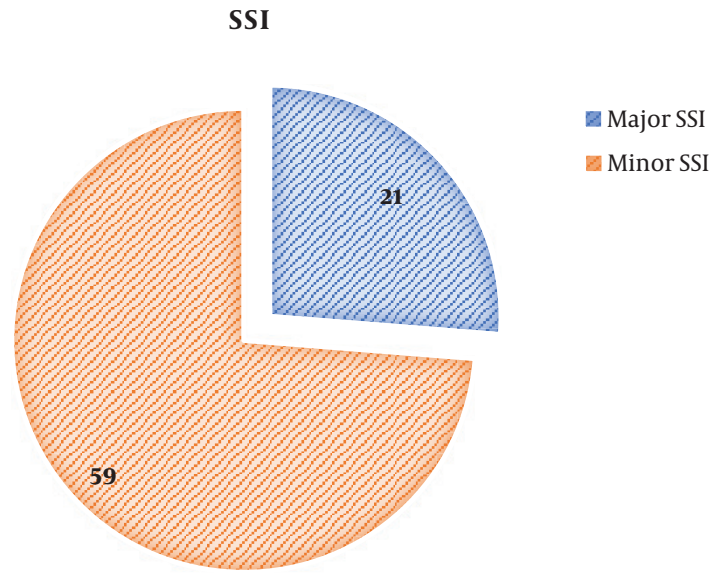

Figure 6. Distribution of SSI into major and minor SSI in a 1000-bed tertiary-care teaching hospital

Gram-negative bacilli were predominant causes of SSI, with Acinetobacter baumannii at the rate of 19/80 (23.75\%), followed by Pseudomonas aeruginosa with the rate of $14 / 80$ (17.5\%). This trend of gram-negative bacilli dominating gram-positive cocci has been observed in other studies (18-21). Acinetobacter species are oxidase-negative, opportunistic pathogens that have emerged as major causes of SSI in this setting. Acinetobacter has also been isolated from food (including hospital food), suctioning equipment, infusion pumps, sinks, pillows, mattresses, ventilator equipment, tap water, bed rails, stainless steel trolleys, humidifiers, soap dispensers, and other sources $(22,23)$.

Pseudomonas aeruginosa is a Gram-negative opportunistic pathogen found in moist environments like hospital water systems. Multidrug-resistant strains are associated with increased morbidity and mortality. E. coli, accounting for $15 \%$ of SSI in this study, is a Gram-negative intestinal bacterium responsible for the endogenous infection. In other parts of the world such as Turkey (22.8\%) and Brazil (15.3\%), E. coli has been the most prevalent pathogen in SSI. Klebsiella pneumoniae as a gram-negative multidrugresistant organism prevalent in hospital settings was responsible for $12.5 \%$ of SSI in this study (24-26).

Staphylococcus aureus is a gram-positive coccus responsible for $12.5 \%$ of the total SSI in this study. It is accountable for a significant proportion of all SSI cases worldwide mainly affecting the skin and soft tissue. MRSA and vancomycin-resistant staphylococcus aureus (VRSA) in hospital settings are difficult to treat (27). The study was limited by short duration and limited sample size; however, it can aptly serve a pilot study for planning multicenter prospective studies on SSI to delineate etiology, 


\section{SURGICAL SITE INFECTION}

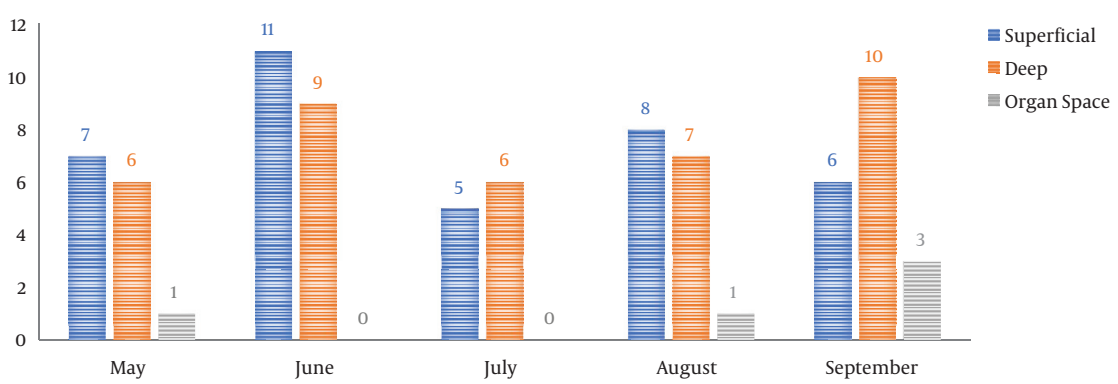

Figure 7. Incidence of various types of SSI in a 1000-bed tertiary-care teaching hospital

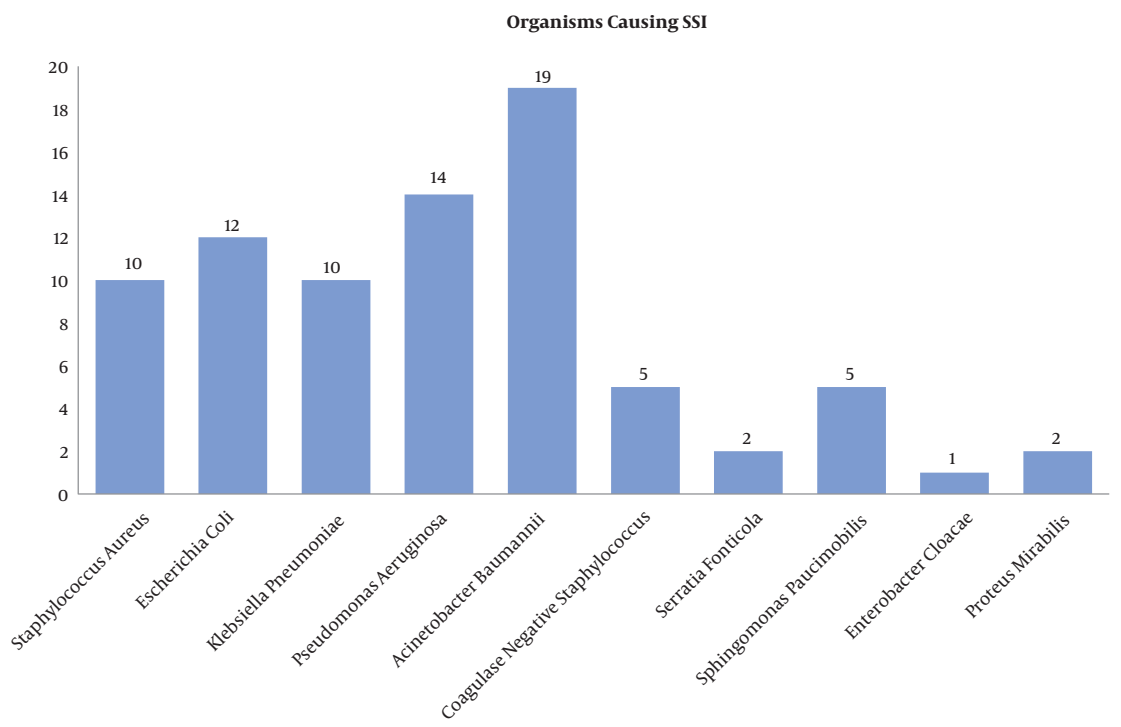

Figure 8. Organisms causing SSI in 1000-bed tertiary-care teaching hospital

prognosis, and prevention strategies.

\subsection{Conclusion}

The rate of SSI in this study was comparable to the rates in India and the world. A pre-existing medical illness, prolonged operating time, and wound contamination strongly predispose to surgical site infection. Antimicrobial prophylaxis, hand-hygiene, reduced duration of surgery, and drain care are effective in reducing the incidence of SSI. Periodic surveillance of SSI can guide infection control committees in process surveillance.

\section{Footnotes}

Authors' Contribution: Lt Col Inam Danish Khan, Akansha Yadav, Umesh Kapoor, and Ishitta Joshi developed the original idea and the protocol, abstracted and analyzed data, wrote the manuscript, and were guarantors. Lt Col Inam Danish Khan and Rahul Pandey developed the protocol, abstracted data, and prepared the manuscript. Ananta Kumar Naik, Jyoti Prakash, Abimannyu Chowdhury, Megha Brijwal, Geetanjali Gonimadatala, Nehal Bhuttay, and Anuradha Makkar were involved in critical revision of the manuscript for important intellectual content and data collection.

Conflict of Interests: None.

Ethical Approval: The study was approved by the Institutional Ethics and Scientific Committee.

Funding/Support: None. 


\section{References}

1. Watanabe A, Kohnoe S, Shimabukuro R, Yamanaka T, Iso Y, Baba H, et al. Risk factors associated with surgical site infection in upper and lower gastrointestinal surgery. Surg Today. 2008;38(5):404-12. doi: 10.1007/s00595-007-3637-y. [PubMed: 18560962].

2. Khan ID, Basu A, Kiran S, Trivedi S, Pandit P, Chattoraj A. DeviceAssociated Healthcare-Associated Infections (DA-HAI) and the caveat of multiresistance in a multidisciplinary intensive care unit. Med J Armed Forces India. 2017;73(3):222-31. doi: 10.1016/j.mjafi.2016.10.008. [PubMed: 28790779]. [PubMed Central: PMC5533520].

3. World Health Organization. Protocol for surgical site infection surveillance with a focus on settings with limited resources. Geneva: World Health Organization; 2018.

4. Khan ID, Khan SA, Asima B, Hussaini SB, Zakiuddin M, Faisal FA. Morbidity and mortality amongst Indian Hajj pilgrims: A 3-year experience of Indian Hajj medical mission in mass-gathering medicine. $J$ Infect Public Health. 2018;11(2):165-70. doi: 10.1016/j.jiph.2017.06.004. [PubMed: 28668659]. [PubMed Central: PMC7102688].

5. Khan ID, Sahni AK, Bharadwaj R, Lall M, Jindal AK, Sashindran VK. Emerging organisms in a tertiary healthcare set up. Med JArmed Forces India. 2014;70(2):120-8. doi: 10.1016/j.mjafi.2013.09.005. [PubMed: 24843199]. [PubMed Central: PMC4017190].

6. Sahu C, Konar J, Banerjee S; et al. Nasal carriage of MRSA amongst health care workers in a tertiary care hospital. Int J Current Med and Pharma Res. 2015.

7. Danish Khan I, Mohan Gupta R, Sen S, Rajmohan KS, Kumar Jindal A, Makkar A, et al. Emerging antimicrobial resistance and evolving healthcare: Dangerous crossroads for the community and the military. Journal of Archives in Military Medicine. 2017;5(3).

8. Owens CD, Stoessel K. Surgical site infections: epidemiology, microbiology and prevention. Journal of Hospital Infection. 2008;70:3-10. doi: 10.1016/s0195-6701(08)60017-1.

9. Jindal AK, Pandya K, Khan ID. Antimicrobial resistance: A public health challenge. Med J Armed Forces India. 2015;71(2):178-81. doi: 10.1016/j.mjafi.2014.04.011. [PubMed: 25859082]. [PubMed Central: PMC4388962]

10. Khan ID, Lall M, Sen S, Ninawe SM, Chandola P. Multiresistant Elizabethkingia meningoseptica infections in tertiary care. Med J Armed Forces India. 2015;71(3):282-6. doi: 10.1016/j.mjafi.2014.02.002. [PubMed: 26288498]. [PubMed Central: PMC4534552]

11. Khan ID, Gupta N, Rangan NM, Singh R, Sharma AK, Khurana A, et al. Evaluation of pre and post analytical variables in clinical microbiology services in multidisciplinary ICU of a medical college and tertiary care hospital. Journal of Basic and Clinical Medicine. 2016;5(1).

12. Khan ID, Mukherjee T, Gupta S, Haleem S, Sahni AK, Banerjee S, et al. Ochrobactrum anthropi sepsis in intensive tertiary care. Journal of Basic and Clinical Medicine. 2014;3(1).

13. CDC. Data of the National Hospital Discharge Survey. 2017.

14. Cheng H, Chen BP, Soleas IM, Ferko NC, Cameron CG, Hinoul P. Prolonged Operative Duration Increases Risk of Surgical Site Infections: A Systematic Review. Surg Infect (Larchmt). 2017;18(6):722-
35. doi: 10.1089/sur.2017.089. [PubMed: 28832271]. [PubMed Central: PMC5685201].

15. Kaye KS, Schmit K, Pieper C, Sloane R, Caughlan KF, Sexton DJ, et al. The effect of increasing age on the risk of surgical site infection.JInfect Dis. 2005;191(7):1056-62. doi: 10.1086/428626. [PubMed: 15747239].

16. Butler SO, Btaiche IF, Alaniz C. Relationship between hyperglycemia and infection in critically ill patients. Pharmacother apy. 2005;25(7):963-76. doi: 10.1592/phco.2005.25.7.963. [PubMed: 16006275].

17. Black JD, de Haydu C, Fan L, Sheth SS. Surgical site infections in gynecology. Obstet Gynecol Surv. 2014;69(8):501-10. doi: 10.1097/OGX.0000000000000102. [PubMed: 25144613].

18. Anvikar AR, Deshmukh AB, Karyakarte RP, Damle AS, Patwardhan NS, Malik AK, et al. One year prospective study of 3280 surgical wounds. Indian journal of medical microbiology. 1999;17(3):129.

19. Shahane V, Bhawal S, Lele U. Surgical site infections: A one year prospective study in a tertiary care center. Int J Health Sci (Qassim). 2012;6(1):79-84. doi: 10.12816/0005976. [PubMed: 23267307]. [PubMed Central: PMC3523786].

20. Tripathy BS, Roy N. Post-operative wound sepsis. Indian J Med 1984;46(6):285-8.

21. Kamath N, Swaminathan R, Sonawane J. Bacteriological profile of surgical site infections in a tertiary care center in Navi Mumbai [abstract]. Proceedings of the 16th Maharashtra Chapter Conference of IAMM. 2010.

22. Richards MJ, Edwards JR, Culver DH, Gaynes RP. Nosocomial infections in medical intensive care units in the United States. National Nosocomial Infections Surveillance System. Crit Care Med. 1999;27(5):887-92. doi: 10.1097/00003246-199905000-00020. [PubMed: 10362409].

23. Fournier PE, Richet H. The epidemiology and control of Acinetobacter baumannii in health care facilities. Clin Infect Dis. 2006;42(5):692-9. doi: 10.1086/500202. [PubMed: 16447117]

24. Turner KH, Everett J, Trivedi U, Rumbaugh KP, Whiteley M. Requirements for Pseudomonas aeruginosa acute burn and chronic surgical wound infection. PLoS Genet. 2014;10(7). e1004518. doi: 10.1371/journal.pgen.1004518. [PubMed: 25057820]. [PubMed Central: PMC4109851].

25. Moremi N, Claus H, Vogel U, Mshana SE. Surveillance of surgical site infections by Pseudomonas aeruginosa and strain characterization in Tanzanian hospitals does not provide proof for a role of hospital water plumbing systems in transmission. Antimicrob Resist Infect Control. 2017;6:56. doi: 10.1186/s13756-017-0216-x. [PubMed: 28593044] [PubMed Central: PMC5461769].

26. Isik O, Kaya E, Dundar HZ, Sarkut P. Surgical site infection: reassessment of the risk factors. Chirurgia (Bucur). 2015;110(5):457-61.

27. Hidron AI, Edwards JR, Patel J, Horan TC, Sievert DM, Pollock DA, et al NHSN annual update: antimicrobial-resistant pathogens associated with healthcare-associated infections: annual summary of data reported to the National Healthcare Safety Network at the Centers for Disease Control and Prevention, 2006-2007. Infect Control Hosp Epidemiol.2008;29(11):996-1011. doi: 10.1086/591861. [PubMed: 18947320]. 